\title{
Wae Grahe dan Wamlana: Dua Dialek Bahasa Buru dengan Daya Hidup yang Berbeda
}

\author{
Mukhamdanah \\ Badan Pengembangandan Pembinaan Bahasa \\ mukhamdanah@gmail.com
}

\begin{abstract}
Abstrak
Perubahan ekosistem linguistik dan khususnya faktor ekonomi dan marjinalisasi masyarakat pribumi yang bersifat intrinsik membawa dampak bagi situasi pergeseran bahasa. Pergeseran bahasa dan penyebabnya merupakan hal yang mendapat perhatian cukup besar dari para linguis atau ahli bahasa. Bahasa yang mempunyai potensi terancam punah dianggap mengalami penurunan yang cepat dalam jumlah dan kualitas, terutama pada wilayah yang menggunakan bahasa lain dengan nilai atau potensi tertentu. Kajian ini berupaya menjelaskan daya hidup bahasa Buru terutama dialek Buru Utara, di Wamlana yang merupakan daerah pesisir yang dipenuhi oleh para pendatang serta daya hidup dialek Rana di Wae Grahe sebagai daerah yang masih "asli”. Kontak bahasa, perkawinan campuran, urbanisasi, prestise bahasa lain, system pendidikan formal yang menggunakan bahasa nasional, serta kurangnya transmisi bahasa ibu antargenerasi menjadi ancaman terhadap kelangsungan sebuah bahasa. Dengan menggunakan data primer dari 54 responden di dua wilayah tadi, serta dengan analisis data secara kuantitatif dan kualitatif, kajian ini memaparkan daya hidup bahasa Buru di Wamlana dan Wae Grahe. Hasil kajian menunjukkan bahwa daya hidup dua dialek ini tidak sama. Daya hidup yang cenderung kuat dimiliki oleh dialek Wae Grahe sebagai dialek yang dituturkan di daerah yang cenderung homogen (secara budaya dan agama), jauh dari pusat pemerintahan dan pusat ekonomi, kontak bahasa yang kecil, serta masih terjadinya transmisi bahasa ibu. Sementaraitu, dialek utara di Wamlana cenderung berada pada daya hidu prendah. Perkawinan antarsuku, masyarakat yang heterogen, kontak bahasa, serta tidak adanya transmisi bahasa ibu, menjadi penyebabnya.
\end{abstract}

Kata kunci: ekosistem, kontak bahasa, pergeseran, daya hidup

\section{PENDAHULUAN}

Pembicaran tentang munculnya bahasa-bahasa yang terancam telah menjadi perhatian serius dalam lingkup internasional terutama dengan makin meningkatnya infomasi atau publikasi tentang ancaman yang meningkat yang tidak hanya pada bidang linguistic, budaya, dan keanekaragaman hayati di dunia. Sejumlah lembaga pustaka telah menerangkan isu-isu penting dan sedang berusaha meningkatkan kepedulian di kalangan masyarakat aslidan penutur jati serta kepada orang-orang yang mempunyai kepedulian terhadap bahasa, baik dalam bidang kebahasaan maupun interdispliner, instansi pemerintah, organisasi non pemerintah, dan masyarakat umum agar segera memberikan kontribusi dalam upaya memberikan dukungan terhadap pelestarian budaya dan bahasa yang terancam punah (Florey, 2010: 4)

Bahasa-bahasa yang terancam dapat didefinisikan sebagai bahasa-bahasa yang domain penggunaannya sudah sangat terbatas, dan khususnya, tidak termasuk bahasa yang biasa digunakan untuk berinteraksi dengan anak-anak. Biasanya, bahasa-bahasa tersebut hanya digunakan oleh orang-orang yang dewasa atau orang-orang yang sudah berusia lanjut.

Indonesia merupakan negara ke-30 dari segi keragaman jumlah bahasa daerah (Lewis, 2009:39). Namun, sebagian besar bahasa daerah di Indonesia termasuk pada kategori terancam punah. Beberapa laporan penelitian menunjukkan bahwa ancaman kepunahan bahasa tidak hanya terjadi pada bahasa dengan jumlah penutur kecil tetapi juga terjadi pada bahasa-bahasa dengan 
jumlah penutur besar. Gunarwan (1982) melihat adanya potensi punahnya bahasa Jawa, bahasa Melayu, dan bahasa Bali. Namun, ia memprediksikan kepunahan sebuah bahasa berlangsung cukup lama, yakni sekitar 75-100 tahun atau tiga generasi. Jika penanganan kebahasaan berjalan dalam ketidakseimbangan antara bahasa Indonesia dan bahasa daerah sebagai bahasa minoritas, serta antara bahasa minoritas dengan bahasa daerah mayoritas lainnya, lambat laun kepunahan bahasa akan terjadi. Spolsy sebagaimana terdapat dalam Katubi (2004:4) menyatakan bahwa kelompok etnis menggunakan sebagai salah satu pengidentifikasi diri yang paling maknawi.

Kepunahan bahasa harus dihambat karena bahasa merupakan ekspresi nilai, norma, aturan, adat, dan kebiasaan, bahkan juga ekspresi dari perilaku politik suatu kebudayaan. Keberagaman bahasa daerah di Indonesia merupakan laboratorium sosial budaya, yang dapat dikaji untuk mengkaji kearifan lokal, sistem nilai, dan kosmologi.

Pada kegiatan pengumpulan data kajian vitalitas bahasa daerah di Pulau Buru, Maluku, ditemukan beberapa hal menarik. Pertama, bahasa Buru yang memilik jumlah penutur besar, pada daerah tertentu ternyata penggunaan bahasa Buru mulai menurun. Kedaan ini semakin diperparah dengan masuknya masyarakat dari etnis lain ke P.Buru karena faktor ekonomi. Penambangan emas, makin mudahnya sarana transportasi dan semakin tingginya mobilitas penduduk, juga turut menjadi sebab menurunnya penggunaan bahasa Buru di P.Buru.

Untuk mengetahui bagaimana daya hidup atau vitalitas bahasa Buru, kajian awal ini dilakukan. Kajian ini antara lain untuk mengetahui daya hidup bahasa Buru serta melakukan dokumentasi terhadap kosakata bahasa Buru. Data bahasa ini diharapkan bisa menjadi langkah awal kajian-kajian berikutnya misalnya tentang aspek bahasanya.

Kajian ini bertujuan mendeskripsikan daya hidup bahasa Buru yang dituturkan di wilayah Pulau Buru sebagai tanah asal bahasa Buru. Dua dialek yaitu dialek Rana dan dialek Buru Utara dipilih arena dua wilayah ini mempunyai karakteristik yang berbeda. Dialek Rana dituturkan di wilayah yang agak terpencil, jauh dari pusat ekonomi dan pemerintahan, serta masyarakatnya cenderung homogen. Sementara itu, wilayah Wamlana di Pantai Utara Buru, mempunyai ciri berbeda. Sebagai pusat ekonomi dan pemerintahan, masyarakat yang heterogen, multi suku, multi bahasa, serta akses yang mudah ke pusat pemerintahan dan ekonomi yang lebih besar, pernikahan antarsuku, menyebabkan kontak bahasa juga sering terjadi. Dengan melihat penggunaan atau situasi kebahasaan di kedua wilayah ini, maka tujuan dari kajian ini adalah:

1. Mendeskripsikani situasi kebahasaan dan daya hidup bahasa Buru dialek Rana di Wae Grahe,

2. Mendeskripsikani situasi kebahasaan dan daya hidup bahasa Buru dialek utara, yaitu di Wamlana.

Hasil kajian ini diharapkan dapat melengkapi informasi tentang daya hidup bahasa-bahasa daerah di Indonesia. Dengan mengetahui daya hidup bahasa daerah yang ada di Indonesia,Pemerintah, dalam hal ini Badan Bahasa dapat memberikan prioritas penanganan terhadap bahasa-bahasa tersebut. Tentu saja penanganan harus diprioritaskan terhadap bahasabahasa dengan daya hidup yang rendah.

Populasi kajian ini adalah semua penutur bahasa Buru. Penentuan sampel dilakukan secara acak bertujuan. Sumber data adalah primer, berupa kuesioner yang diberikan kepada 94 responden, terdiri atas 47 responden di Wamlana, dan 47 responden di Wae Grahe. Selain data 
primer, hasil kajian juga akan dilengkapi dengan observasi partisipatif. Hal ini dilakukan agar halhal yang tidak diperoleh dari data primer akan dilengkapi dari data observasi partisipatif tersebut.

Kajian tentang daya hidup dua dialek bahasa Buru yang di Wae Grahe dan Wamlana dilakukan dengan menggunakan metode deskriptif.Data yang diperoleh dari data primer dianalisis secara kuantitatif.Setiap jawaban dari butir pertanyaan diberi bobot.Pilihan jawaban 'Ya' mempunyai bobot 2, dan 'Tidak" mempunyai bobot 1. Dari jawaban inilah akan dihitung nilai rata-rata untuk setip butir pertanyaan. Jika nilai rata-rata berada pada kisaran $1-1.5$, maka akan dikategorikan dengan kecenderungan 'Tidak', semantara nilai rata-rata 1,5 ke atas, dikategorikan dengan kecenderungan ' $Y a$ '. Nilai rata-rata yang diperoleh dari dua wilayah (Wae Grahe dan Wamlana) akan bandingkan. Pada indikator-indikator dengan nilai rata-rata yang tidak sama inilah akan dideskripsikan daya hidup dari dua dialek bahasa Buru.

Dalam kaitannya dengan daya hidup bahasa-bahasa di dunia, Gufran dengan mengutip Krauss (1992:4 10) mengelompokkan bahasa-bahasa di dunia ke dalam tiga tipologi berikut.

1. Bahasa-bahasa yang punah (moribund languages)

Bahasa yang tidak digunakan, dipelajari, atau diperoleh oleh anak-anak sebagai bahasa ibu (mother tongue).

2. Bahasa-bahasa yang terancam punah (endangered languages)

Bahasa-bahasa yang meskipun sekarang masih dipelajari (diperoleh) anak-anak tetapi akan ditinggalkan oleh anak-anak pada abad yang akan datang.

3. Bahasa-bahasa yang masih aman (safe languages)

4. Bahasa-bahasa yang mendapat sokongan dari pemerintah dan memiliki penutur dalam jumlah besar.

Krauss, sebagaimana dikutip Gufran membuat pengelompokan bahasa dalam tiga tipologi di atas berdasarkan jumlah penutur dan bagaimana pemerintah merawat dan memberi perhatian pada bahasa-bahasa. Ia juga menyimpulkan bahwa dari \pm 6.000 bahasa di dunia, $50 \%$ di antaranya termasuk dalam kategori punah (moribund), 40\% dalam kategori terancam punah (endangered), dan hanya $10 \%$ yang masuk kategori aman (safe). Hal ini berarti bahwa banyaknya bahasa yang termasuk dalam kategori punah dan hampir punah jauh lebih banyak jika dibandingkan dengan yang masuk dalam kategori aman, yaitu hanya 600 bahasa. Bahasa-bahasa yang termasuk kategori aman (safe) ini akan terus bertahan karena:

1. bahasa-bahasa tersebut berfungsi sebagai bahasa resmi, dan

2. bahasa-bahasa itu memiliki penutur asli di atas satu juta orang.

Sementara itu, kesepakatan para ahli bahasa di Jerman tahun 2000 tentang kepunahan bahasa (Grimes, 2001) disebutkan bahwa ada beberapa tahap yang dialami suatu bahasa menuju kepunahan, yaitu sebagai berikut.

1. Sangat kritis (critically endangered)

Penuturnya sedikit sekali semua penutur berumur 70 tahun ke atas, usia kakek-nenek, buyut.

2. Sangat terancam (severly endangered)

Semua penuturnya berumur 40 tahun ke atas, usia kakek-nenek.

3. Terancam (endangered) 
Semua penuturnya berusia 20 tahun ke atas; usia orang tua.

4. Mengalami kemunduran (eroding)

Sebagian penutur adalah anak-anak dan kaum tua, anak-anak lain tidak berbicara dengan bahasa ini.

5. Kondisi stabil, mantap, tetapi terancam punah (stable but threatened)

Semua anak-anak dan kaum tua menggunakannya tetapi jumlah penuturnya sedikit.

6. Aman (safe)

Tidak terancam punah, bahasa ini diharapkan dipelajari oleh semua anak dan semua orang dalam etnis tersebut.

Austin (2011:5 - 6) menyatakan kepunahan bahasa dapat disebabkan oleh lima faktor, yaitu (1) ekonomi, misalnya karena pedesaan yang miskin dan upaya perbaikan atau peningkatan ekonomi; (2) dominasi budaya, misalnya dominasi budaya mayoritas yang akan menyebabkan budaya pribumi menjadi atau tinggal cerita; (3) politik, misalnya kebijakan pendidikan nasional yang mengabaikan bahasa lokal atau bahasa setempat; (4) sejarah, misalnya kolonisasi atau penjajahan, batas-batas daerah wilayah yang mejadi peerselisihan, naiknya satu kelompok dan variasi bahasa mereka dalam bidang politik dan kebudayaan yan lebih besar; (5) sikap, misalnya bahasa minoritas selalu diasosiasikan sebagai kelompok miskin, tertinggal, kebutaaksaraan dan kesulitan; sementara itu, bahasa dominan selalu diasosiasikan sebagai sebuah kemajuan, jalan keluar.

Kajian daya hidup dua dialek bahasa Buru akan berpijak pada pandangan yang dikemukan oleh Kraus. Namun, lima faktor yang dikemukan oleh Austin juga akan digunakan sebagai data tambahan untuk melengkapi tinjuan analisis.

Ancaman kepunahan bahasa banyak terjadi di wilayah Indonesia bagian timur.Hal ini karena sebagian besar bahasa mempunyai jumlah penutur yang kecil. Grimes (2009: 90--92) yang telah memulai melakukan kajian atau penelitian di wilayah Maluku tentang bahasa Kayeli dan Hukumina menyebutkan bahwa di Pulau Buru terdapat sekitar 45.000 orang penutur bahasa Buru, termasuk penutur Kayeli, Hukumina, dan bahasa-bahasa yang brhubungan seperti Ambelau, Melayu Ambon, Buton, Sula, Indonesi, dan Tukang Besi.

Mukhamdanah (2016) dalam tulisannya tentang kontak bahasa dan perubahan bahasa pada masyarakat penutur bahasa Buru menyatakan bahwa kontak dialek dan kontak bahasa yang terjadi pada bahasa Buru memungkinkan terjadinya perubahan pada bahasa dan dialeknya. Kajian tersebut mencoba melihat perubahan bahasa yang terjadi pada bahasa Buru yang dituturkan di sekitar Danau Rana dan pesisir utara Pulau Buru karena terjadinya kontak bahasa Buru dengan bahasa Indonesia dan bahasa Melayu Ambon. Dengan menggunakan metode komparatif terhadap kosakata dan struktur frasa dan klausanya serta dengan teknik leksikostatistik yang diambil di tiga wilayah pakai bahasa Buru, yaitu Wamlana, Fogi, dan Rana, hasil kajian tersebut menunjukan bahwa dalam leksikon, dialek Wamlana lebih dekat dengan Rana.

\section{HASIL KAJIAN}

Masyarakat Buru

Penduduk di Pulau Buru, dapat dibedakan antara penduduk asli, autokton, (Geba Bupolo) yang hidup di pegunungan, dan penduduk pendatang, alokton, (Geba Misnit) yang hidup di daerah 
pesisir pantai. Saat ini jumlah Geba Misnit relatif lebih banyak dari Geba Bupolo (Pattinama, 2005). Alokton dan autokton selalu menyatakan diri sebagai orang Buru.

Geba Fuka adalah Geba Bupolo yang mendiami daerah pegunungan. Geba Fuka Unen adalah mereka yang hidup di sentral pulau, dimana ada Rana dan Gunung Date. Yang tinggal di lerenglereng gunung menamakan diri Geba Fuka Fafan sedangkanyang tinggal di pesisir pantai berkat program Departemen Sosial untuk pemukiman kembali bersama dengan alokton dinamakan Geba Masin.

Berdasarkan penggolongan di atas, maka penduduk Buru terdiri atas geba bupolo sebagai penduduk asli dan geba masnit yang merupakan penduduk pendatang. Dengan terdapatnya dua jenis penduduk di Pulau Buru ini, maka kontak budaya dan kontak bahasa sangat mungkin terjadi. Artinya, telah terjadi juga kontak budaya dan kontak bahasa antara bahasa Buru dengan bahasa Sula, Sanana, Ternate, Kei, Banda, dan Ambon maupun dengan Buton, Bugis, Jawa, dan beberapa bahasa di Sumatra. Kontak bahasa dan kontak budaya antar penutur bahasa dan pendukung budaya dapat menjadi sebab pergeseran bahasa.Pergeseran bahasa inilah yang akhirnya turut mempengaruhi daya hidup sebuah bahasa.

Jika dilihat berdasarkan letaknya, selain mempunyai kedekatan dengan wilayah-wilayah lain di Maluku seperti Seram, Buru juga dekat dengan dengan Kepulauan Sula, misalnya Sanana, dan Taliabu. Karena kedekatan inilah maka Pulau Buru banyak menjadi daerah sasaran pendatang (imigran lokal) baik yang datang dari Seram, Ambon, Jawa, maupun dari Kepulauan Sula. Orangorang dari Sulawesi, terutama dari Bugis dan Buton juga banyak mendiami wilayah-wilayah Buru, terutama di daerah-daerah pesisir.

\section{Bahasa Buru dan Dialeknya}

Dalam buku Bahasa dan Peta Bahasa di Indonesia yang diterbitkan Pusat Pembinaan dan Pengembangan Bahasa (1998:20) disebutkan bahwa bahasa Buru di diantaranya digunakan oleh masyarakat di Wamlana dan Fogi. SIL (2006) mengelompokkan atau membagi bahasa Buru (Boeroe) atas empat dialek, yaitu dialek Masarete (Buru Selatan), Wae Sama (Waesama), Buru Tengah (Rana, Wae Geren, Wae Kabo), dan Fogi (Li Emteban, Tomahu).Wurm dan Hatori (1981: 83) dalam Language Atlas of the PasificArea sebagaimana terdapat dalam Grimes (2000:73) menyebutkan bahwa di Pulau Buru hanya ada satu bahasa, yaitu bahasa Buru (termasuk Kayeli dan Ambelau). Bahasa Buru menjadi hal yang menarik terutama karena terjadinya pernikahan antarsuku, pola migrasi, modernisasi, kekuasaan yang rendah, serta faktor politik.

Grimes (2000:74) membedakan dialek-dialek dominan dalam bahasa Buru. Dialek-dialek dalam bahasa Buru tersebut yaitu dialek Lisela, Fogi, Masarete, Wae Sama, dan Rana.

Dialek Rana dituturkan oleh sebagian masyarakat yang tinggal di sekitar danau yang terlatak di pusat atau tengah-tengah Pulau Buru.Selain dialek Rana, sebagian dari mereka juga menuturkan dialek Li Geren (Grimes, 2000: 98).Dialek Rana ini juga dianggap Buru 'asli'

\section{Daya Hidup Bahasa Buru di Wae Grahe dan Wamlana}

Transmisi bahasa yang masih terjadi, penggunaan dalam berbagai ranah (ranah penggunaan bahasa daerah), serta tingkat penguasaan yang baik bahasa Buru, akan membuat daya hidup bahasa Buru tetap tinggi. Daya hidup akan semakin rendah jika ketiga hal di atas tidak terpenuhi. 
Tabel berikut ini menyajikan bagaimana indikator transmisi bahasa Buru, penguasaan oleh anak-anak (generasi muda), serta penggunaan bahasa Buru di Wae Grahe dan Wamlana.Data atau nilai rata-rata berikut diperoleh berdasarkan persepesi responden.

Tabel 1.

Transmisi, Penggunaan, dan Penguasaan Bahasa Berdasarkan Nilai Rata-rata

\begin{tabular}{|c|l|c|c|}
\hline \multirow{2}{*}{ No. } & \multicolumn{2}{|c|}{ Indikator } & \multicolumn{2}{c|}{ Nilai Rata-rata } \\
\cline { 3 - 4 } & & Wae Grahe & Wamlana \\
\hline 1 & Transmisi BB antargenerasi & $1.9 / \mathrm{Ya}$ & $1.2 /$ Tidak \\
\hline 2 & Penguasaan BB oleh Keluarga & $1.7 / \mathrm{Ya}$ & $1.3 /$ Tidak \\
\hline 3 & Penguasaan anak-anak terhadap BB & $1.8 / \mathrm{Ya}$ & $1 /$ Tidak \\
\hline 4 & Pengunaan BB dalam ranah rumah tangga (bahasa lisan) & $1.9 / \mathrm{Ya}$ & $1.1 /$ Tidak \\
\hline
\end{tabular}

Berdasarkan Tabel 1 diketahui bahwa pada masyarakat penutur bahasa Buru di Wae Grahe, faktor-faktor yang menjadi penyebab melemahnya daya hidup bahasa Buru, tidak terjadi. Hal ini bisa dilihat bahwa masih terjadi transmisi atau pewarisan bahasa ibu (bahasa Buru) pada keluarga-kaluarga atau dari para orang tua di Wae Grahe. Bahasa Buru juga masih digunakan dalam ranah keluarga, ranah rumah tangga. Penggunaan bahasa ini sangat mungkin terjadi karena adanya penguasaan bahasa Buru oleh keluarga. Hasil dari masih terjadinya transmisi bahasa ibu, penguasaan bahasa Buru oleh anggota keluarga, serta masih digunakannya bahasa tersebut dalam ranah rumah tangga adalah penguasaan bahasa daerah oleh anak-anak atau generasi muda.

Sebaliknya, pada masyarakat di Wamlana, transmisi bahasa ibu tidak lagi terjadi. Hal ini disebabkan orang tua lebih mengajarkan bahasa Melayu/bahasa Indonesia kepada anak-anak mereka dengan alasan agar anak-anak mereka tidak akan mengalami kesulitan pada saat mulai bersekolah. Masyarakat Wamlana yang cenderung heterogen serta cukup tingginya perkawinan antaretnis juga menjadi pilihan para orang tua untuk tidak mengajarkan bahasa Buru kepada anakanak mereka.

Tidak terjadinya transmisi bahasa ibu, tidak digunakannya bahasa daerah dalam ranah keluarga dan penguasaan bahasa Buru yang tidak dimiliki oleh anggota keluarga, menyebabkan anak-anak generasi penutur bahasa Buru, tidak lagi menguasai bahasa Buru.

Jika dilihat kedwibahasaan responden, kedua kelompok responden juga mempunyai tingkat penguasaan yang berbeda terhadap bahasa lain. Hal ini dapat dilihat pada Tabel 2 berikut.

Tabel 2.

Kedwibahasaan Responden Berdasarkan Nilai Rata-rata

\begin{tabular}{|c|l|c|c|}
\hline \multirow{2}{*}{ No. } & \multicolumn{2}{|c|}{ Indikator } & \multicolumn{2}{c|}{ Nilai Rata-rata } \\
\cline { 3 - 4 } & & Wae Grahe & Wamlana \\
\hline 1 & Penguasaan bahasa Indonesia & $1.1 /$ Tidak & $1.5 / \mathrm{Ya}$ \\
\hline 2 & Penguasaan BD lain & $1.1 /$ Tidak & $1.6 / \mathrm{Ya}$ \\
\hline
\end{tabular}

Berdasarkan Tabel 2, masyarakat di Wae Grahe cenderung tidak atau kurang menguasai bahasa Indonesia. Penguasaan terhadap bahasa daerah lain juga tidak terjadi. Hal ini disebabkan masyarakat Wae Grahe merupakan masyarakat yang homogen. Hanya ada beberapa orang dari suku lain yang tinggal di sini, yaitu guru di sekolah di Wae Grahe. 
Hal yang berbeda justru dialami oleh masysrakat di Wamlana. Masyarakat di sini cenderung heterogen dan merupakan masyarakat yang bilingual. Hal ini disebabkan karena telah terjadinya kontak bahasa yang cukup lama dengan suku lain, misalnya Bugis, Sula, dan Jawa yang sudah tinggal di Wamlana selama beberapa generasi.

Penggunaan bahasa pada ranah agama oleh masyarakat di Wae Grahe dan Wamlana disajikan pada Tabel 3 berikut.

Tabel 3.

Penggunaan Bahasa pada Ranah Agama berdasarkan Nilai Rata-rata

\begin{tabular}{|c|c|c|c|}
\hline \multirow{2}{*}{ No. } & \multicolumn{2}{|c|}{ Indikator } & \multicolumn{2}{|c|}{ Nilai Rata-rata } \\
\cline { 3 - 4 } & & Wae Grahe & Wamlana \\
\hline 1 & Penggunaan BB dalam ranah agama (ketika berdoa) & $1.9 / \mathrm{Ya}$ & $1.2 /$ Tidak \\
\hline 2 & Penggunaan BB dalam ranah agama (ibadah) & $1.9 / \mathrm{Ya}$ & $1.1 /$ Tidak \\
\hline
\end{tabular}

Pada ranah agama, bahasa Buru masih digunakan oleh penutur di Wae Grahe. Perlu ditambahkan di sini, bahwa masyarakat di Wae Grahe masih menganut sistem kepercayaan

Pada masyarakat penutur di Wamlana, yang terjadi adalah sebaliknya. Bahasa Indonesia digunakan dalam ranah agama oleh masyarakat di Wamlana. Artinya, telah terjadi pergeseran penggunaan bahasa dari bahasa daerah ke bahasa Indonesia.

Sebuah bahasa akan mempunyai daya hidup yang tinggi jika bahasa tersebut berfungsi sebagai bahasa nasional atau pemerintah mengembangkan bahasa daerah tersebut.

Tabel 4.

Penggunaan Bahasa pada Ranah Pemerintah serta Regulsi Pemerintah terhadap Bahasa Buru Berdasarkan Niali Rata-rata

\begin{tabular}{|c|l|c|c|}
\hline \multirow{2}{*}{ No. } & \multicolumn{2}{|c|}{ Indikator } & \multicolumn{2}{c|}{ Nilai Rata-rata } \\
\cline { 3 - 4 } & & Wae Grahe & Wamlana \\
\hline 1 & Penggunaan BB dalam ranah formal (pemerintahan) & $1.5 /$ Ya & $1 /$ Tidak \\
\hline 2 & Kewajiban penggunaan BB dalam layanan publik & $1.5 /$ Ya & $1.3 /$ Tidak \\
\hline 3 & Pemerintah mengembangkan dan melindungi BB & $1.7 /$ Ya & $1.4 /$ Tidak \\
\hline
\end{tabular}

Pada Tabel 4 disajikan bahwa pada layanan publik bahasa Buru juga tidak digunakan di Wamlana sementara di Wae Grahe masih digunakan. Tabel 5 berikut menyajikan bagaimana mobilitas responden, penguasaan bahasa Buru oleh suku lain, ada atau tidaknya izin dari swasta mengenai penggunaan bahasa Buru.

Tabel 5.

Tingkat Mobilitas, Penguasaan Bahasa Buru oleh Etnis lain, serta Izin Penggunaan Bahasa Oleh Swasta Berdasarkan Nilai Rata--rata

\begin{tabular}{|c|l|l|l|}
\hline \multirow{2}{*}{ No. Indikator } & \multicolumn{2}{|c|}{ Nilai Rata-rata } \\
\cline { 3 - 4 } & & Wae Grahe & Wamlana \\
\hline 1 & Penutur BB banyak yang tinggal di tempat lain & $1.3 /$ Tidak & $1.6 /$ Ya \\
\hline 2 & Perusahaan swasta mengizinkan penggunaan BB & $1.7 /$ Ya & $1.3 /$ Tidak \\
\hline 3 & Kunjungan etnis lain ke daerah tuturan & $1 /$ Tidak & $1.6 /$ Ya \\
\hline 4 & Penguasaan BB oleh etnis lain & $1.1 /$ Tidak & $1.1 /$ Tidak \\
\hline
\end{tabular}


Kelompok penutur bahasa Buru di Wae Grahe cenderung tidak banyak yang meninggalkan daerahnya. Hal ini dapat dilihat dari sedikitnya kelompok penutur dari Wae Grahe yang tinggal di tempat lain. Kunjungan etnis lain ke Wae Grahe juga tidak banyak. Sedikitnya atau kecilnya penutur lain yang ke Wae Grahe serta penutur Wae Grahe yang tinggal di daerah lain disebabkan oleh cukup sulitnya akses dan sarana transportasi ke Wae Grahe. Wilayah yang tidak mudah dijangkau ini menyebabkan kunjungan etnis lain juga kecil. Kecilnya kontak dengan suku lain ini menyebabkan bahasa Buru dialek Rana di Wae Grahe tidak dikuasai oleh pihak lain.

Hal yang berbeda terjadi pada masyarakat di Wamlana. Sebagai kota kecamatan, pusat ekonomi sekaligus pusat pemerintahan, Wamlana dihuni oleh berbagai suku. Akses yang mudah dari dan ke daerah lain, menyebabkan intensitas kontak bahasa juga tinggi. Kontak bahasa dengan intensitas yang tinggi serta cenderung digunakannya bahasa Melayu/bahasa Indonesia sebagai bahasa dalam pergaulan umum, membuat daya hidup bahasa Buru di Wamlana semakin menurun.

\section{PENUTUP}

\section{Simpulan}

Bahasa Buru dialek Rana yang dituturkan di Wae Grahe mempunyai daya hidup yang cenderung lebih baik dibandingkan dengan dialek Lisela (Buru Utara) yang dituturkan di Wamlana; artinya, daya hidup bahasa pada dialek yang di Wamlana adalah rendah.

Perbedaan daya hidup kedua dialek Rana di Wae Grahe dan dialek Lisela di Wamlana antara lain ditunjukkan oleh hal-hal berikut.

1. Transmisi bahasa ibu antargenerasi, penguasaan yang baik oleh anggota keluarga, penguasaan bahasa ini oleh anak-anak generasi muda, masih terjadi dan dimiliki oleh penutur dialek Rana di Wae Grahe.Sebaliknya, hal ini tidak terjadi di Wamlana.

2. Penguasaan bahasa Indonesia dan bahasa daerah lain cenderung tidak dimiliki oleh penutur di Wae Grahe. Sebaliknya, penguasaan bahasa Indonesia dan bahasa daerah lain cenderung dimiliki oleh masyarakat di Wamlana.

3. Pada ranah agama, bahasa Buru masih digunakan oleh penutur di Wae Grahe, sementara di Wamlana, tidak digunakan.

4. Pada ranah formal, dialek Rana masih digunakan di Wae Grahe. Sebaliknya, di Wamlana, bahasa Buru cenderung tidak digunakan. Hal ini disebabkan masyarakat di Wamlana cenderung heterogen; masyarakatnya penutur dari beberapa bahasa.

5. Penutur di Wae Grahe, cenderung mempunyai mobilitas yang rendah karena kendala transportasi dan wilayah yang tidak mudah dijangkau. Kontak bahasa, cenderung rendah. Kontak bahasa yang rendah membuat daya hidup bahasa tidak mudah terancam. Sebaliknya, Wamlana, sebagai pusat pemerintahan dan pusat kegiatan ekonomi, mempunyai tingkat intensitas kunjungan antaretnsi yang tinggi. Hal ini menyebabkan kontak bahasa dan kontak budaya yang terjadi, juga cenderung lebih tinggi. Kontak bahasa yang tinggi akan menimbulkan terajadinya pergeseran bahasa. Pergeseran bahasa akan berdampak pada 'menangnya' bahasa dominan dan melemahnya bahasa lain yang tidak dominan. 


\section{Rekomendasi}

1. Perlu dilakukan pembinaan terhadap penutur bahasa ini terutama di Wamlana agar tumbuh sikap positif terhadap bahasa daerah.

2. Perlu dilakukan revitalisasi bahasa Buru terutama pada dialek Lisela di Wamlana.

3. Perlu dilakukan pendokumentasian data bahasanya treutama pada dialek-dialek yang mempunyai daya hidup rendah. Hal ini perlu dilakukan agar kejadian seperti yang terjadi pada dialek Kayeli tidak terulang.

\section{DAFTAR PUSTAKA}

Florey, Margaret. 2010. Endangered Languages of Austronesia. Oxford: University Press

Grimes, Charles E. 2000. "Defining Speech of Communities on Buru Island” dalam Spices from the East: Papers in Languages of Eastern Indonesia. Canberra: Pasific Linguistics.

Heidi, Johnson. 2004. Language Documentation and Archiving, or How to Build a Better Corpus. The Hans Rausing: Endangered Language Project.

Lewis, M. Paul. Ed. 2009.Ethnologue: Language of the Word. Dallas: SIL International.

Mukhamdanah, 2016. "Kontak Bahasa dan Perubahan Bahasa: Kasus pada Bahasa Buru di Pulau Buru, Maluku”. Makalah disampaikan pada Seminar Nasional di Ambon, Maluku.

Pattinama, Max Marcus J. "Kekuatan Bahasa dalam Rasa, Karya, dan Karsa: (Suatu Ajakan untuk Revitalisasi Bahasa Buru sebagai Mata Ajaran Mulok)”. Dalam http://maxmjpattinama.unpatti.org/tag/penyelamatan-bahasa-daerah/. Diakses 23 Oktober 2015.

SIL International Cabang Jakarta: 2006. Bahasa-bahasa di Indonesia. Jakarta: SIL Internasional, Cabang Indonesia.

Sugono, Dendy Ed. 1998. Bahasa dan Peta Bahasa di Indonesia. Jakarta: Badan Pembinaan dan Pengembangan Bahasa 